\title{
ONDE ESTÃO OS LEÕES? UM OLHAR SOBRE AS EXPOSIÇÕES DO INSTITUTO MOREIRA SALLES
}

MANUELA THAMANI

UNIVERSIDADE DE SÃO PAULO

SÃO PAULO, SÃO PAULO, BRASIL MANUELATHAMANI@GMAIL.COM 


\section{ONDE ESTÃO OS LEÕES? UM OLHAR SOBRE AS EXPOSIÇÕES DO INSTITUTO MOREIRA SALLES.}

Resumo: O presente artigo tem como objetivo analisar o (des) equilíbrio étnico-racial e de gênero nas exposições do Instituto Moreira Salles (Higienópolis e Paulista), e visa a partir desses elementos promover uma reflexão sobre a invisibilidade de determinados grupos historicamente margeados no protagonismo artístico. Os dados foram levantados a partir do site do Instituto Moreira Salles, e foram validados em entrevistas efetuadas com representantes da instituição.

Palavras-chave: gênero; raça; racismo institucional; arte.

\section{¿DÓNDE ESTÁN LOS LEONES? UNA MIRADA SOBRE LAS EXPOSI- CIONES DEL INSTITUTO MOREIRA SALLES.}

Resumen: El presente artículo tiene como objetivo analizar el (des) equilibrio étnico-racial y de género en las exposiciones del Instituto Moreira Salles (Higienópolis y Paulista), y pretende a partir de esos elementos promover una reflexión sobre la invisibilidad de determinados grupos históricamente margeados en el protagonismo artístico. Los datos fueron levantados a partir del sitio del Instituto Moreira Salles, y fueron validados en entrevistas efectuadas con representantes de la institución.

Palabras clave: género; raza; racismo institucional; arte.

\section{WHERE ARE THE LIONS? A LOOK AT THE EXHIBITIONS OF INSTITU- TO MOREIRA SALLES.}

Abstract: This article aims to analyze the ethno-racial and gender (im) balance in the exhibitions of Instituto Moreira Salles (Higienópolis and Paulista) and aims to promote a reflection on the invisibility of certain historically marginalized groups in artistic protagonism. The data were collected from the Moreira Salles Institute website and validated in interviews with representatives of the institution.

Key words: gender; race; institutional racism; art. 


\section{INTRODUÇÃO}

Amealhando, organizando e difundindo conhecimento desde sua fundação, o IMS quer também gerar conhecimento a partir de seus acervos. Nesse sentido, tem procurado estabelecer convênios e intercâmbios com universidades, brasileiras e estrangeiras, e com outros museus. Pesquisa é meta a ser seguida. Memória está em quase tudo o que o IMS faz. Ser guardião do passado é missão das mais nobres. De um passado que não fique estagnado, mas que seja também fundamental para entender o presente e enfrentar o futuro. Na melhor inspiração de sua história, o IMS quer construir legados culturais. É a isso que vem se devotando. (Pinheiro, s.d).

No texto de abertura do site do Instituto Moreira Salles (www.ims.com. br), Flávio Pinheiro, que assina o texto como superintendente executivo do instituto, apresenta alguns dos principais anseios que norteiam essa instituição. Em tom contundente, o autor arremata a importância da compreensão do passado, para se obter uma visão crítica da atualidade, bem como orientar a construção de um futuro. Pinheiro ainda descreve o Instituto Moreira Salles (IMS) como uma das iniciativas protagonistas do cenário cultural brasileiro, diz que entre as quatro áreas exploradas pela instituição, a saber: fotografia, música, literatura e iconografia, a primeira é responsável por tornar o IMS a mais importante instituição de fotografia do Brasil.

Tomando como base uma análise das exposições do IMS-Higienópolis e IMS-Paulista, durante o período de 1996 a 2018, e que estão registradas no site da instituição, este artigo parte da minha inquietação quanto à escassa presença de mulheres e homens não brancos enquanto autoria das obras expostas nesses locais. Postulo assim uma reflexão acerca da necessidade de múltiplas identidades, no que tange a produção e visibilidade artística, como aspecto indispensável para a construção de narrativas plurais dentro do universo da arte.

\section{UM POUCO DE PASSADO PARA ENTENDER O PRESENTE}

Até que os leões inventem as suas próprias histórias, os caçadores serão sempre os heróis das narrativas de caça é um provérbio africano que resume na perfeição a importância em se dar voz aos diferentes sujeitos de uma sociedade, enaltecendo pluralidade de perspectivas e sentidos acerca de 
relatos.

Historicamente no Brasil, as narrativas dos africanos e povos indígenas, bem como de seus descendentes, foram silenciadas ou margeadas no âmbito da museologia e crítica da arte, como corolário do processo de colonização brasileiro, caracterizado pela a escravização de diversos grupos étnicos africanos e indígenas, que deflagrou em uma hierarquia étnico-social que se estabelece por matrizes de opressão'. Nessa seara, o racismo se configura como uma das principais características do sistema de opressão brasileiro, estando esse pautado em uma crença na existência das raças naturalmente hierarquizadas pela relação intrínseca entre o físico e o moral, o físico e o intelecto, o físico e o cultural (MUNANGA, 2003).

Na década de 1990, com a crescente cobrança e demanda do movimento negro por determinadas atitudes do Estado brasileiro, o conceito de racismo institucional emerge como desestabilizador e com intuito de se pensar uma nova pauta de ações em prol da igualdade racial.

Arivaldo Santos de Souza, em "Racismo Institucional: para compreender o conceito", explica a ideia por trás dessa definição:

Os aparatos institucionais de uma dada sociedade encontram- se a serviço dos grupos hegemônicos que os criam e fazem com que funcionem para a reprodução do sistema que lhe confere significado e existência. Alguém que esteja operando esse sistema poderá produzir resultados raciais injustamente diferenciados ainda que não tenha intenção de fazê-lo. Embora esse tipo de racismo possa ser de difícil detecção, suas manifestações são observáveis por meio dos padrões de sistemática desigualdade produzida pelas burocracias do sistema, que, por sua vez, ao lado das estruturas, formam as instituições. (SOUZA, 2011, p.80).

É importante observar nesse sentido que a reprodução do racismo institucional, muitas vezes não está ligada à intencionalidade do sujeito. Por meio de mecanismos ideológicos, políticos e simbólicos, essa frente de racismo pode estar introjetada na subjetividade do indivíduo.

Essa reflexão nos ajuda a pensar o paradoxo em que vivemos na so-

$1 \quad$ Adotamos aqui o conceito trabalhado por Collins (2000) em seu livro Black Feminist Thought, no qual a autora propõe o conceito de "matrizes de opressão" como uma abordagem interseccional metodológica para tratar do lugar imposto à mulher negra. 
ciedade brasileira, um país que reconhece a presença do racismo, mas que não encontra sujeitos racistas, como revela uma pesquisa realizada pelo Datafolha em 1995 em que 89\% das pessoas entrevistadas afirmaram haver preconceito de cor contra negros no país, mas só 10\% reconhecem ter preconceito (Schwarcz, 2001, p.77).

Ainda que em velocidade tímida, não data de hoje o interesse de pesquisadores acerca da situação dos afro-brasileiros nas questões econômicas, sociais e culturais. Órgãos internacionais também dirigem seus olhares para esses grupos. Em 13 de Dezembro de 2013, o Grupo de Trabalho das Nações Unidas sobre Afrodescendentes divulgou um comunicado sobre a visita oficial realizada ao Brasil durante dezembro daquele ano.

Terminantemente conclui:

Os afro-brasileiros constituem mais da metade da população brasileira, no entanto, são sub-representados e invisíveis na maioria das estruturas de poder, nos meios de comunicação e no setor privado. Esta situação tem origem na discriminação estrutural, que se baseia em mecanismos históricos de exclusão e estereótipos negativos, reforçados pela pobreza, marginalização política, econômica, social e cultural.

Embora o Brasil tenha avançado na redução da pobreza, da pobreza extrema e das taxas de desigualdade, processo do qual os afro-brasileiros se beneficiaram, constatamos que ainda há um grande contraste entre a precariedade da situação dos negros brasileiros e o elevado crescimento econômico do país. Os afro-brasileiros não serão integralmente considerados como cidadãos plenos sem uma justa distribuição do poder econômico, político e cultural. (ORGANIZAÇÃO DAS NAÇÕES UNIDAS, 2013).

O Brasil é o país que concentra a maior população negra² fora da África3; os negros também são a maioria da população brasileira, 52,9\% - segundo

2 Segundo dados do último Censo do Instituto Brasileiro de Geografia e Estatística (IBGE), realizado em 2010, 97 milhões de pessoas se autodeclaram negras (pretas ou pardas) contra 91 milhões de pessoas brancas. Outras cerca de 2,5 milhões se consideram amarelas ou indígenas.

3 PEREIRA, Dulce Maria. A face negra do Brasil multicultural. Dispónível em: < http:// www.dominiopublico.gov.br> acesso em 01 de junho de 2018. 
dados do IBGE de 2014. Se a afrodescendência caracteriza a sociedade brasileira, o reconhecimento e afirmação da negritude e de seus atores, nos espaços culturais, é processo fundamental na construção da identidade cultural brasileira, sobretudo pela sua histórica fragmentação - resultado da violenta colonização escravagista.

A construção da identidade negra está inserida na complexa formação da cultura nacional brasileira, Hall (2015) vai nos alertar que as culturas nacionais são formadas por símbolos e representações, além das instituições culturais. Afirma ainda que essa composição vai nos influenciar sobre a concepção que temos de nós mesmos, ou seja, atua em nosso modo de se tornar sujeito.

Embora cada eixo da tríade: símbolos, representações e instituições culturais, suscite um debate interessante, aqui trazemos à baila a discussão acerca da predominância racial e de gênero dos sujeitos artistas, pelo viés das instituições culturais. Elucidando a identidade étnica-racial como aspecto fundante para aceitação, reconhecimento e autoafirmação social e cultural.

Na pós-modernidade a construção de identidade se dá por inúmeras frentes. Tivemos um deslocamento de crença em identidades fixas e imutáveis, para uma discussão sobre subjetividade dotada de significados maleáveis, percebidos de maneira fragmentária em função dos imaginários dos sujeitos. Portanto, vivemos em uma sociedade em que os sujeitos possuem identidades híbridas.

Tal hibridização também pode se refletir na compreensão de uma mostra museológica. Isto é, uma exposição de arte pode gerar relação identitária desde múltiplas abordagens, a exemplo, essa construção pode se dar a partir de sua proposta conceitual, das representações abordadas nas obras, das técnicas utilizadas, mas também da própria identidade de gênero e racial dos artistas.

Não raro nos referimos aos artistas como seres dotados de uma capacidade superior, cruzam-se esforços para qualificar obras de arte como produções intelectuais, não apenas trabalho manual. Conferimos ao artista seu importante papel na sociedade, enquanto representante das artes liberales $^{4}$. E ressaltamos a importância de melhor compreendê-lo, bem como suas obras, como resultantes dos olhares sociais que constituíram a história

$4 \quad$ Warnke (2001) define as artes liberales como aquela que é exercida por um homem livre e com prazer desinteressado. 
de um tempo específico, portanto ele também pode ser entendido como um ser histórico, e em tal papel deve ser compreendido a partir das relações que o permeia.

O que acontece com a relação identitária quando os autores das obras são majoritariamente homens branco centrados? O olhar do artista consegue distanciar-se o suficiente para construir narrativas para além de seu lugar de fala? Esboçamos uma reflexão para essas perguntas utilizando uma passagem do conto O Espelho de João Guimarães Rosa, em que diz: "E os próprios olhos, e cada um de nós, padecem viciação de origem, defeitos com que cresceram e a que se afizeram, mais e mais [...] Os olhos, por enquanto, são a porta do engano; duvide dele, dos seus, não de mim." 5

À luz da provocação feita por Rosa, acredito que as diversidades de gênero e étnico-racial entre artistas que irão compor periódicas exposições, trata-se de elemento fundamental se almejamos construir as muitas possibilidades de narrativas dos sujeitos sobre si e sobre o mundo.

\section{O PROTAGONISMO NORMATIZADO NO IMS}

Castells (199, p.22), em referência aos atores sociais, pondera que a identidade é o processo de construção de significado com base em um conjunto de atributos culturais inter-relacionados, de modo a coexistirem identidades múltiplas. Nessa explanação sobre o conceito de identidade, o autor tenciona a distinção entre identidades e papéis, enquanto identidades organizam significados, os papéis organizam funções.

Trazer à baila questionamentos, nomeadamente: por quem? Como? Para que? Ajudam-nos a refletir em que contexto se expressa os determinantes simbólicos das identidades. É basilar também reconhecer que tais determinantes se figuram estruturalmente nas organizações e instituições dominantes na sociedade. Conforme Castells (1999, p.24) alusivo ao desenvolvimento de identidades, o ser humano não é predeterminado a uma identidade imutável, de maneira que pode se deslocar entre posições, na perspectiva de um ser em processo de construção.

Ao explorar o processo social de construção da identidade, Castells (1999, p.24) nos alerta para a realidade de que essa produção se dá no âmbito caracterizado por relações de poder, e que podem ser caracterizadas em

5 ROSA, João Guimarães. Primeiras Estórias. Rio de Janeiro, Nova Fronteira, 2001, p.120 
três formas e origens:

- Identidade legitimadora: estabelecida pelas organizações e instituições dominantes da sociedade, com o intuito de amplificar e fundamentar a sua dominação sobre os atores sociais.

- Identidade de resistência: promovida por atores sociais que se encontram em posição desvalorizada e/ou estigmatizadas pelo principal dominante, construindo alternativas de resistência e sobrevivência.

- Identidade-projeto: quando os atores sociais, por meio de material cultural o qual possa usufruir, constroem uma nova identidade com possibilidade de redefinição de sua posição na sociedade e, por corolário, pode modificar o conjunto da estrutura social.

O racismo institucional opera principalmente no nível das identidades legitimadoras, se configura nas formas como elas funcionam, seguindo padrões normativos enquanto ocupação de espaços e, assim, contribuindo para a naturalização de hierarquia racial. Essa vertente de racismo é pérfida por ser silenciosa, ao passo que é abrangente e complexa, agindo em termos de visibilidade na cultura, na política e na ética. Não se expressa por atos explícitos ou declarados de discriminação, orientados manifestamente por motivos raciais; atua de forma difusa nos modos de funcionamento cotidiano de instituições e organizações, que operam de forma diferenciada na distribuição de oportunidades aos diferentes grupos raciais.

Em seu livro Crítica da Razão Negra, Mbembe (2018, p.12) conceitua o negro como "ser este (ou aquele) que vemos quando nada se vê, quando nada compreendemos e, sobretudo, quando nada queremos compreender". O paradoxo apresentado Mbembe, a invisibilidade do negro nos variados setores da sociedade, também se aplicou ao corpus deste artigo, IMS-Higienópolis e IMS-Paulista.

Como indicado anteriormente, a instituição foi selecionada devido ao seu autodeclarado compromisso com a área de pesquisa, bem como por seu renome em termos de instituição de arte. Por meio de uma pesquisa exploratória no site, e entrevistas com funcionários do instituto, obtive a confirmação dos dados apresentados a seguir. As informações sobre as exposições disponibilizadas no site datam do período que compreende os anos de 1996 a 2018. Assim em cima desses anos foi realizada a análise. Elaborei uma categorização por título da exposição; se essa abordava um artista somente (solo) ou se múltiplos artistas; gênero do artista; raça, período e início da exposição e local em que foi realizada. 
Desse filtro inicial, foram levantadas 91 exposições, porém a análise foi filtrada para somente as exposições solo, devido ao protagonismo e consequentemente maior visibilidade dada ao artista. Dessa forma, partimos para 70 exposições, entre 1996 e 2018, no IMS-Higienópolis e IMS-Paulista.

Quadro 1 - IMS Higienópolis

\begin{tabular}{|c|c|c|c|c|c|}
\hline Nome da exposição & Nome artista & Gênero & Etnia & Período & Ano \\
\hline $\begin{array}{l}\text { Gregório Gruber - Pinturas, } \\
\text { desenhos e esculturas }\end{array}$ & \begin{tabular}{|l|} 
Gregório \\
Gruber
\end{tabular} & Homem & Branco/a & $\begin{array}{l}10 / 10 / 1996 \mathrm{a} \\
26 / 01 / 1997\end{array}$ & 1996 \\
\hline $\begin{array}{l}\text { Paul Harro-Harring - Es- } \\
\text { boços tropicais do Brasil }\end{array}$ & $\begin{array}{l}\text { Paul Har- } \\
\text { ro-Harring }\end{array}$ & Homem & Branco/a & $\begin{array}{l}06 / 08 / 1996 \text { a } \\
06 / 10 / 1996\end{array}$ & 1996 \\
\hline $\begin{array}{l}\text { Sérgio Fingermann - Pin- } \\
\text { turas }\end{array}$ & $\begin{array}{l}\text { Sérgio Fin- } \\
\text { germann }\end{array}$ & Homem & Branco/a & $\begin{array}{l}30 / 05 / 1996 a \\
04 / 08 / 1996 \\
\end{array}$ & 1996 \\
\hline $\begin{array}{l}\text { Alberto Alexandre Mar- } \\
\text { tins - Esculturas, relevos e } \\
\text { gravuras }\end{array}$ & $\begin{array}{l}\text { Alberto } \\
\text { Alexandre } \\
\text { Martins } \\
\end{array}$ & Homem & Branco/a & $\begin{array}{l}09 / 04 / 1996 a \\
04 / 08 / 1996\end{array}$ & 1996 \\
\hline $\begin{array}{l}\text { Recife de João Cabral - } \\
\text { Fotografias }\end{array}$ & João Cabral & Homem & Branco/a & $\begin{array}{l}05 / 03 / 1996 a \\
31 / 03 / 1996 \\
\end{array}$ & 1996 \\
\hline $\begin{array}{l}\text { São Paulo de Lévi-Strauss - } \\
\text { Fotografias }\end{array}$ & $\begin{array}{l}\text { Claude Lévi- } \\
\text { Strauss }\end{array}$ & Homem & Branco/a & $\begin{array}{l}30 / 01 / 1996 a \\
03 / 03 / 1996 \\
\end{array}$ & 1996 \\
\hline $\begin{array}{l}\text { São Paulo de Vincenzo } \\
\text { Pastore - Fotografias }\end{array}$ & \begin{tabular}{|l|} 
Vincenzo \\
Pastore
\end{tabular} & Homem & Branco/a & $\begin{array}{l}30 / 01 / 1997 a \\
20 / 04 / 1997 \\
\end{array}$ & 1997 \\
\hline $\begin{array}{l}\text { Antonio Henrique Amaral - } \\
\text { Da gravura à pintura }\end{array}$ & $\begin{array}{l}\text { Antonio Hen- } \\
\text { rique Amaral }\end{array}$ & Homem & Branco/a & $\begin{array}{l}24 / 04 / 1997 a \\
27 / 07 / 1997 \\
\end{array}$ & 1997 \\
\hline Amador Perez - Desenhos & \begin{tabular}{|l|} 
Amador \\
Perez
\end{tabular} & Homem & Branco/a & $\begin{array}{l}\text { 31/07/1997 a } \\
02 / 11 / 1997\end{array}$ & 1997 \\
\hline $\begin{array}{l}\text { Piza: Trabalhos recentes } \\
\text { - aquarela, desenhos e } \\
\text { colagens }\end{array}$ & $\begin{array}{l}\text { Arthur Luiz } \\
\text { Piza }\end{array}$ & Homem & Branco/a & $\begin{array}{l}17 / 09 / 1998 a \\
21 / 02 / 1999\end{array}$ & 1998 \\
\hline $\begin{array}{l}\text { Hildegard Rosenthal: ce- } \\
\text { nas urbanas - Fotografias }\end{array}$ & $\begin{array}{l}\text { Hildegard } \\
\text { Rosenthal }\end{array}$ & Mulher & Branco/a & $\begin{array}{l}\text { 25/02/1999a } \\
30 / 05 / 1999\end{array}$ & 1999 \\
\hline $\begin{array}{l}\text { Retratos - Fotografias de } \\
\text { Madalena Schwartz }\end{array}$ & $\begin{array}{l}\text { Madalena } \\
\text { Schwartz } \\
\end{array}$ & Mulher & Branco/a & $\begin{array}{l}26 / 08 / 1999 a \\
07 / 11 / 1999 \\
\end{array}$ & 1999 \\
\hline $\begin{array}{l}\text { Candido Portinari - Desen- } \\
\text { hos }\end{array}$ & $\begin{array}{l}\text { Candido Por- } \\
\text { tinari }\end{array}$ & Homem & Branco/a & $\begin{array}{l}11 / 11 / 1999 a \\
09 / 04 / 2000\end{array}$ & 1999 \\
\hline $\begin{array}{l}\text { Gravuras do Novo Mun- } \\
\text { do - Gravuras e mapas do } \\
\text { século XVII - John Ogiby }\end{array}$ & John Ogiby & Homem & Branco/a & $\begin{array}{l}11 / 11 / 1999 \text { a } \\
09 / 04 / 2000\end{array}$ & 1999 \\
\hline $\begin{array}{l}\text { Christiane Burrill - Fotoco- } \\
\text { lagens }\end{array}$ & $\begin{array}{l}\text { Christiane } \\
\text { Burrill } \\
\end{array}$ & Mulher & Branco/a & $\begin{array}{l}05 / 04 / 2001 \mathrm{a} \\
17 / 06 / 2001\end{array}$ & 2001 \\
\hline $\begin{array}{l}\text { Roberto Magalhães - De- } \\
\text { senhos }\end{array}$ & \begin{tabular}{|l} 
Roberto \\
Magalhães \\
\end{tabular} & Homem & Branco/a & $\begin{array}{l}21 / 06 / 2001 a \\
30 / 09 / 2001 \\
\end{array}$ & 2001 \\
\hline $\begin{array}{l}\text { Mário Zavagli - Paisagens } \\
\text { mineiras }\end{array}$ & $\begin{array}{l}\text { Mário Za- } \\
\text { vagli }\end{array}$ & Homem & Branco/a & $\begin{array}{l}\text { 04/10/2001a } \\
20 / 01 / 2002\end{array}$ & 2001 \\
\hline
\end{tabular}


CADERNOS DE COMUNICAÇÃO

UNIVERSIDADE FEDERAL DE SANTA MARIA

\begin{tabular}{|c|c|c|c|c|c|}
\hline Odires Mlászho & $\begin{array}{l}\text { Odires } \\
\text { Mlászho }\end{array}$ & Homem & Branco/a & $\begin{array}{l}29 / 01 / 2002 \mathrm{a} \\
17 / 03 / 2002 \\
\end{array}$ & 2002 \\
\hline $\begin{array}{l}\text { O Brasil de Marcel Gauth- } \\
\text { erot }\end{array}$ & $\begin{array}{l}\text { Marcel } \\
\text { Gautherot }\end{array}$ & Homem & Branco/a & $\begin{array}{l}21 / 03 / 2002 \mathrm{a} \\
25 / 08 / 2002\end{array}$ & 2002 \\
\hline Walter Carvalho, fotógrafo & $\begin{array}{l}\text { Walter Car- } \\
\text { valho }\end{array}$ & Homem & Branco/a & $\begin{array}{l}03 / 07 / 2003 a \\
26 / 10 / 2003\end{array}$ & 2003 \\
\hline $\begin{array}{l}\text { Gonçalo Ivo: aquarelas e } \\
\text { têmperas }\end{array}$ & Gonçalo Ivo & Homem & Branco/a & $\begin{array}{l}30 / 10 / 2003 a \\
25 / 01 / 2004 \\
\end{array}$ & 2003 \\
\hline $\begin{array}{l}\text { São Paulo contemporânea, } \\
\text { por Cristiano Mascaro }\end{array}$ & $\begin{array}{l}\text { Cristiano } \\
\text { Mascaro }\end{array}$ & Homem & Branco/a & $\begin{array}{l}29 / 01 / 2004 a \\
27 / 06 / 2004 \\
\end{array}$ & 2004 \\
\hline $\begin{array}{l}\text { Francisco Toledo: obra } \\
\text { gráfica }\end{array}$ & $\begin{array}{l}\text { Francisco } \\
\text { Toledo } \\
\end{array}$ & Homem & Branco/a & $\begin{array}{l}07 / 07 / 2004 \text { a } \\
29 / 08 / 2004 \\
\end{array}$ & 2004 \\
\hline Nemer: aquarelas recentes & $\begin{array}{l}\text { José Alberto } \\
\text { Nemer }\end{array}$ & Homem & Branco/a & $\begin{array}{l}\text { 02/09/2004a } \\
27 / 02 / 2005 \\
\end{array}$ & 2005 \\
\hline $\begin{array}{l}\text { Paraíso - Desenhos inédi- } \\
\text { tos de Arthur Luiz Piza }\end{array}$ & $\begin{array}{l}\text { Arthur Luiz } \\
\text { Piza }\end{array}$ & Homem & Branco/a & $\begin{array}{l}08 / 03 / 2005 \mathrm{a} \\
15 / 05 / 2005 \\
\end{array}$ & 2005 \\
\hline $\begin{array}{l}\text { Os 'reclames' de Fluvio } \\
\text { Pennacchi: primórdios da } \\
\text { propaganda brasileira }\end{array}$ & $\begin{array}{l}\text { Fluvio Pen- } \\
\text { nacchi }\end{array}$ & Mulher & Branco/a & $\begin{array}{l}18 / 05 / 2005 \mathrm{a} \\
18 / 09 / 2005\end{array}$ & 2005 \\
\hline O mundo de Alice Brill & Alice Brill & Mulher & Branco/a & $\begin{array}{l}27 / 09 / 2005 a \\
05 / 03 / 2006\end{array}$ & 2006 \\
\hline O Brasil de Marc Ferrez & Marc Ferrez & Homem & Branco/a & $\begin{array}{l}16 / 11 / 2006 a \\
04 / 03 / 2007\end{array}$ & 2006 \\
\hline Manfredo de Souzanetto & $\begin{array}{l}\text { Manfredo de } \\
\text { Souzanetto } \\
\end{array}$ & Homem & Branco/a & $\begin{array}{l}13 / 07 / 2006 \mathrm{a} \\
12 / 11 / 2006 \\
\end{array}$ & 2006 \\
\hline $\begin{array}{l}\text { Marcello Grassmann - De- } \\
\text { senhos }\end{array}$ & $\begin{array}{l}\text { Marcello } \\
\text { Grassmann }\end{array}$ & Homem & Branco/a & $\begin{array}{l}\text { 12/04/2006a } \\
09 / 07 / 2006\end{array}$ & 2007 \\
\hline $\begin{array}{l}\text { Horacio Coppola: visões } \\
\text { de Buenos Aires }\end{array}$ & $\begin{array}{l}\text { Horacio Cop- } \\
\text { pola }\end{array}$ & Homem & Branco/a & $\begin{array}{l}29 / 11 / 2007 a \\
24 / 02 / 2008\end{array}$ & 2007 \\
\hline Georges Leuzinger & $\begin{array}{l}\text { Georges } \\
\text { Leuzinger }\end{array}$ & Homem & Branco/a & \begin{tabular}{|l|}
$20 / 09 / 2007$ a \\
$18 / 11 / 2007$ \\
\end{tabular} & 2007 \\
\hline Bez Batti & $\begin{array}{l}\text { João Bez } \\
\text { Batti }\end{array}$ & Homem & Branco/a & $\begin{array}{l}15 / 03 / 2007 a \\
08 / 07 / 2007\end{array}$ & 2008 \\
\hline Samson Flexor & $\begin{array}{l}\text { Samson } \\
\text { Flexor }\end{array}$ & Homem & Branco/a & $\begin{array}{l}07 / 08 / 2008 a \\
26 / 10 / 2008 \\
\end{array}$ & 2008 \\
\hline $\begin{array}{l}\text { Claudio Mubarac - Ideias } \\
\text { de fabricação: pequeno } \\
\text { atlas }\end{array}$ & $\begin{array}{l}\text { Claudio Mub- } \\
\text { arac }\end{array}$ & Homem & Branco/a & $\begin{array}{l}15 / 05 / 2008 a \\
03 / 08 / 2008\end{array}$ & 2008 \\
\hline $\begin{array}{l}\text { Interiores - Fotografias de } \\
\text { Patrick Bogner }\end{array}$ & $\begin{array}{l}\text { Patrick } \\
\text { Bogner } \\
\end{array}$ & Homem & Branco/a & $\begin{array}{l}28 / 02 / 2008 \text { a } \\
11 / 05 / 2008 \\
\end{array}$ & 2009 \\
\hline Marcel Gautherot: Norte & $\begin{array}{l}\text { Marcel } \\
\text { Gautherot }\end{array}$ & Homem & Branco/a & $\begin{array}{l}\text { 25/11/2009a } \\
21 / 03 / 2010\end{array}$ & 2009 \\
\hline Otto Supakoff & $\begin{array}{l}\text { Otto Supa- } \\
\text { koff }\end{array}$ & Homem & Branco/a & $\begin{array}{l}21 / 08 / 2009 a \\
22 / 11 / 2009\end{array}$ & 2009 \\
\hline
\end{tabular}


CADERNOS DE COMUNICAÇÃO

UNIVERSIDADE FEDERAL DE SANTA MARIA

\begin{tabular}{|c|c|c|c|c|c|}
\hline Jindrich Strei - Fotografias & Jindrich Strei & Homem & Branco/a & $\begin{array}{l}30 / 06 / 2009 \\
\text { a 16/08/2009 }\end{array}$ & 2009 \\
\hline $\begin{array}{l}\text { O Louvre e seus visitantes } \\
\text { - Fotografias de Alécio de } \\
\text { Andrade }\end{array}$ & $\begin{array}{l}\text { Alécio de } \\
\text { Andrade }\end{array}$ & Homem & Branco/a & $\begin{array}{l}23 / 04 / 2009 a \\
21 / 06 / 2009\end{array}$ & 2009 \\
\hline José Medeiros & $\begin{array}{l}\text { José Me- } \\
\text { deiros }\end{array}$ & Homem & Branco/a & $\begin{array}{l}29 / 01 / 2009 \text { a } \\
12 / 04 / 2009 \\
\end{array}$ & 2009 \\
\hline $\begin{array}{l}\text { Fred Sandback - O espaço } \\
\text { nas entrelinhas }\end{array}$ & $\begin{array}{l}\text { Fred Sand- } \\
\text { back }\end{array}$ & Homem & Branco/a & $\begin{array}{l}17 / 08 / 2010 a \\
24 / 10 / 2010\end{array}$ & 2010 \\
\hline $\begin{array}{l}\text { Anna Mariani - Pinturas e } \\
\text { platibandas }\end{array}$ & Anna Mariani & Mulher & Branco/a & $\begin{array}{l}\text { 08/06/2010 a } \\
08 / 08 / 2010 \\
\end{array}$ & 2010 \\
\hline Artur Pereira - Esculturas & Artur Pereira & Homem & Negro/a & $\begin{array}{l}30 / 03 / 2010 a \\
06 / 06 / 2010\end{array}$ & 2010 \\
\hline Mira Schendel, pintora & $\begin{array}{l}\text { Mira Schen- } \\
\text { del }\end{array}$ & Mulher & Branco/a & $\begin{array}{l}06 / 12 / 2011 a \\
11 / 03 / 2012\end{array}$ & 2011 \\
\hline $\begin{array}{l}\text { Charles Landseer - Desen- } \\
\text { hos e aquarelas de Portu- } \\
\text { gal e do Brasil, } 1825-1826\end{array}$ & $\begin{array}{l}\text { Charles } \\
\text { Landseer }\end{array}$ & Homem & Branco/a & $\begin{array}{l}10 / 05 / 2011 a \\
10 / 07 / 2011\end{array}$ & 2011 \\
\hline $\begin{array}{l}\text { Thomaz Farkas uma anto- } \\
\text { logia pessoal }\end{array}$ & $\begin{array}{l}\text { Thomaz } \\
\text { Farkas }\end{array}$ & Homem & Branco/a & $\begin{array}{l}\text { 27/01/2011 a } \\
03 / 04 / 2011\end{array}$ & 2011 \\
\hline $\begin{array}{l}\text { Luz, cedro e pedra - Es- } \\
\text { culturas do Aleijadinho } \\
\text { fotografadas por Horácio } \\
\text { Coppola }\end{array}$ & $\begin{array}{l}\text { Horácio Cop- } \\
\text { pola }\end{array}$ & Homem & Branco/a & $\begin{array}{l}17 / 07 / 2012 \mathrm{a} \\
11 / 11 / 2012\end{array}$ & 2012 \\
\hline $\begin{array}{l}\text { Manuel Álvares Bravo - } \\
\text { Fotopoesia }\end{array}$ & $\begin{array}{l}\text { Manuel Álva- } \\
\text { res Bravo }\end{array}$ & Homem & Branco/a & $\begin{array}{l}22 / 03 / 2012 a \\
08 / 07 / 2012 \\
\end{array}$ & 2012 \\
\hline $\begin{array}{l}\text { Luigi Ghirri: Pensar por } \\
\text { imagens }\end{array}$ & Luigi Ghirri & Homem & Branco/a & $\begin{array}{l}23 / 11 / 2013 \text { a } \\
26 / 01 / 2014\end{array}$ & 2013 \\
\hline $\begin{array}{l}\text { Face Andina - Fotografias } \\
\text { de Martin Chambi }\end{array}$ & $\begin{array}{l}\text { Martin } \\
\text { Chambi }\end{array}$ & Homem & Andino & $\begin{array}{l}02 / 10 / 2014 a \\
29 / 03 / 2015 \\
\end{array}$ & 2014 \\
\hline $\begin{array}{l}\text { Araújo Porto-Alegre: sin- } \\
\text { gular \& plural }\end{array}$ & $\begin{array}{l}\text { Manuel A. } \\
\text { Porto Alegre }\end{array}$ & Homem & Branco/a & $\begin{array}{l}\text { 05/06/2014a } \\
21 / 09 / 2014 \\
\end{array}$ & 2014 \\
\hline $\begin{array}{l}\text { Lartigue - A vida em movi- } \\
\text { mento }\end{array}$ & $\begin{array}{l}\text { Jacques Hen- } \\
\text { ri Lartigue } \\
\end{array}$ & Homem & Branco/a & $\begin{array}{l}11 / 02 / 2014 \text { a } \\
25 / 05 / 2014 \\
\end{array}$ & 2014 \\
\hline $\begin{array}{l}\text { Alice Brill: impressões ao } \\
\text { rés do chão }\end{array}$ & Alice Brill & Mulher & Branco/a & $\begin{array}{l}24 / 09 / 2015 a \\
07 / 02 / 2016 \\
\end{array}$ & 2015 \\
\hline $\begin{array}{l}\text { David Drew Zingg: imagem } \\
\text { sobre imagem }\end{array}$ & $\begin{array}{l}\text { David Drew } \\
\text { Zingg }\end{array}$ & Homem & Branco/a & $\begin{array}{l}11 / 04 / 2015 a \\
13 / 09 / 2015 \\
\end{array}$ & 2015 \\
\hline $\begin{array}{l}\text { Do arquivo de um corre- } \\
\text { spondente estrangeiro. } \\
\text { Fotografias de Luciano } \\
\text { Carneiro }\end{array}$ & $\begin{array}{l}\text { Luciano Car- } \\
\text { neiro }\end{array}$ & Homem & Branco/a & $\begin{array}{l}20 / 02 / 2016 a \\
17 / 07 / 2016\end{array}$ & 2016 \\
\hline $\begin{array}{l}\text { Vitrines e fachadas, dois } \\
\text { ensaios paulistanos de } \\
\text { Dulce Soares }\end{array}$ & Dulce Soares & Mulher & Branco/a & $\begin{array}{l}30 / 07 / 2016 a \\
20 / 11 / 2016\end{array}$ & 2016 \\
\hline
\end{tabular}


Quadro 2 - IMS Paulista

\begin{tabular}{|c|c|c|c|c|c|}
\hline Nome da exposição & Nome artista & Gênero & Etnia & Período & Ano \\
\hline $\begin{array}{l}\text { The Clock, de Christian } \\
\text { Marclay }\end{array}$ & $\begin{array}{l}\text { Christian Mar- } \\
\text { clay }\end{array}$ & Homem & Branco/a & $\begin{array}{l}20 / 09 \text { a } \\
19 / 11 / 2017\end{array}$ & 2017 \\
\hline $\begin{array}{l}\text { Robert Frank: Os amer- } \\
\text { icanos + Os livros e os } \\
\text { filmes }\end{array}$ & Robert Frank & Homem & Branco/a & $\begin{array}{l}20 / 09 a \\
30 / 12 / 2017\end{array}$ & 2017 \\
\hline $\begin{array}{l}\text { Câmera aberta, de Mi- } \\
\text { chael Wesely }\end{array}$ & $\begin{array}{l}\text { Michael We- } \\
\text { sely }\end{array}$ & Homem & Branco/a & $\begin{array}{l}20 / 09 / 2017 a \\
31 / 12 / 2018\end{array}$ & 2017 \\
\hline $\begin{array}{l}\text { Anri Sala: o momento } \\
\text { presente }\end{array}$ & Anri Sala & Homem & Branco/a & $\begin{array}{l}12 / 12 / 2017 a \\
25 / 03 / 2018\end{array}$ & 2017 \\
\hline $\begin{array}{l}\text { Chichico Alkmin, fo- } \\
\text { tógrafo }\end{array}$ & $\begin{array}{l}\text { Chichico Alk- } \\
\text { min }\end{array}$ & Homem & Branco/a & $\begin{array}{l}23 / 01 \mathrm{a} \\
15 / 04 / 2018 \\
\end{array}$ & 2018 \\
\hline $\begin{array}{l}\text { São Paulo, fora de } \\
\text { alcance. Fotografias de } \\
\text { Mauro Restiffe }\end{array}$ & Mauro Restiffe & Homem & Branco/a & $\begin{array}{l}14 / 04 a \\
26 / 08 / 2018\end{array}$ & 2018 \\
\hline $\begin{array}{l}\text { Íles Flottantes (Se Mon- } \\
\text { et encontrasse Cêzanne, } \\
\text { em Montfavet), de } \\
\text { Douglas Gordon }\end{array}$ & $\begin{array}{l}\text { Douglas Gor- } \\
\text { don }\end{array}$ & Homem & Branco/a & $\begin{array}{l}14 / 04 a \\
26 / 08 / 2018\end{array}$ & 2018 \\
\hline Seydou Keïta & Seydou Keïta & Homem & Negro/a & $\begin{array}{l}\text { 17/04 a } \\
29 / 07 / 2018\end{array}$ & 2018 \\
\hline Irving Penn: centenário & Irving Penn & Homem & Branco/a & $\begin{array}{l}21 / 08 a \\
18 / 11 / 2018\end{array}$ & 2018 \\
\hline Millôr: obra gráfica & $\begin{array}{l}\text { Millôr Fer- } \\
\text { nandes }\end{array}$ & Homem & Branco/a & $\begin{array}{l}18 / 09 a \\
27 / 01 / 2019\end{array}$ & 2018 \\
\hline $\begin{array}{l}\text { Anri Sala: o momento } \\
\text { presente }\end{array}$ & Anri Sala & Homem & Branco/a & $\begin{array}{l}23 / 01 a \\
25 / 03 / 2018\end{array}$ & 2018 \\
\hline $\begin{array}{l}\text { Fotografia e Literatura } \\
\text { nos livros de Maureen } \\
\text { Bisilliat }\end{array}$ & $\begin{array}{l}\text { Maureen Bis- } \\
\text { illiat }\end{array}$ & Mulher & Branco/a & $\begin{array}{l}09 / 10 / 2018 a \\
10 / 03 / 2019\end{array}$ & 2018 \\
\hline $\begin{array}{l}\text { Claudio Andujar: a luta } \\
\text { Yanonami }\end{array}$ & $\begin{array}{l}\text { Claudio Andu- } \\
\text { jar }\end{array}$ & Mulher & Branco/a & $\begin{array}{l}15 / 12 / 2018 a \\
07 / 04 / 2019\end{array}$ & 2018 \\
\hline
\end{tabular}

Das exposições analisadas, nota-se uma concentração de gênero masculino, 60 dos 70 artistas que expuseram nos estabelecimentos são homens. Quando olhamos pela perspectiva racial também prevalece outra concentração, notamos que 67 dos 70 artistas das exposições analisadas são brancos, contra apenas 3 não brancos.

A totalidade dos artistas não brancos é composta pelo gênero masculino, ou seja, temos o pessoas do gênero feminino entre os artistas não brancos.

A força dos números mostra a falta de equilíbrio tanto de gênero como de raça, a que fiz referência anteriormente. No microcosmo pesquisado, re- 
flete-se o comportamento estrutural da sociedade, em que homens brancos encontram-se amplamente representados nas estruturas de poder, enquanto é baixa, ou até mesmo nula, a representatividade de mulheres não brancas nessas mesmas estruturas de poder.

Quais as consequências dessa situação para a lógica de construção de identidade no campo da arte? Há alguma alternativa para que esses artistas preteridos passem a conquistar esses espaços? Canclini (2012, p.177) vai dizer em seu livro A Sociedade sem Relato que nesta época de arte pós-autônoma, "os artistas redesenham seus programas criativos para se colocar flexivelmente no que resta dos campos artísticos e em outros espaços e redes". Embora Canclini não tenha feito uma referência declarada ao termo "programa" conceituado por Flusser (2008), acreditamos que os autores estão em diálogo quanto à percepção de que um artista, ao compreender determinados comportamentos de uma sociedade, pode jogar com essas informações e produzir outras narrativas. Flusser explica essa possibilidade:

O "artista" deixa de ser visto enquanto criador e passa a ser visto enquanto jogador que brinca com pedaços disponíveis de informação. Esta é precisamente a definição do termo diálogo: troca de pedaços disponíveis de informação. No entanto, o artista brinca com o propósito de produção de nova informação. Ele delibera. Ele participa de diálogos a fim de, deliberadamente, produzir algo imprevisto. (FLUSSER, 2008, p. 122)

À luz desse encadeamento do brincar, numa perspectiva de subversão do programa, posso citar o caso da artista pop Beyoncé ${ }^{6}$ e de seu marido Jay- $\mathrm{Z}^{7}$ que, sob o nome de The Carters, recentemente lançaram um videoclipe intitulado Apeshit. A obra visual foi filmada num dos maiores museus do mundo e grande representante da arte mundial, o Louvre. Com mais de 60 milhões de visualizações, a obra faz uma série de críticas, por meio de signos e significantes, em torno da representatividade racial, da violência contra a população negra, objetificação da mulher negra, entre outros elementos. Ao locar um dos mais renomados museus do mundo, preenchê-lo com diver-

6 Beyoncé Giselle Knowles-Carter é uma cantora, compositora e atriz norte-americana.

7 Shawn Corey Carter é um rapper, compositor, produtor e homem de negócios norte-americano. 
sos artistas negros, e apontar diversos aspectos de uma sociedade racista, Beyoncé e Jay-Z jogam, e estabelecem um grande diálogo com a crença de Flusser, no sentido do jogar como a única maneira viável de exercício de liberdade. Em seu exercício futurista de caracterização da sociedade telemática, Flusser vai dizer:

De repente, as pessoas se tornariam conscientes das virtualidades dialógicas inerentes a imagens: que são infinitamente maiores que as virtualidades dos textos, já que superfícies se compõem por infinidade de linhas. De tal consciência imaginística nova se abririam horizontes para diálogo infinitamente mais informativos que os diálogos unidimensionais da sociedade histórica precedente. (FLUSSER, 2008, p. 116)

Nesse sentido entendemos que o papel da museologia, pela qual elaborei crítica ao IMS (Higienópolis e Paulista), não seja apenas o de apresentar discursos e dar visibilidade, aos quais se beneficiam pequenos grupos. Seu papel é mais do que isso: tem o compromisso de gerar uma prática que possa ser reflexo da sociedade - tanto na composição de seu quadro de artistas, quanto na representatividade construída nas obras.

\section{CONSIDERAÇÕES FINAIS}

A inspiração para este artigo nasceu a partir da experiência desta pesquisadora ao visitar a exposição Seydou Keïta - fotógrafo negro malinês - no IMS-Paulista. Em meio à farta e elaborada produção artística de Keïta, e por ser apreciadora das exposições daquele local com considerada frequência, me tencionou a seguinte reflexão: a despeito de ter lembrando-me de obras em que houve representação de pessoas negras, qual teria sido a última vez que havia contemplado uma exposição solo, de um artista negro naquele estabelecimento? E a partir desta indagação caminhei para o desenvolvimento de uma pesquisa tímida, mas urgente em seu propósito, uma reflexão que contemple o desequilíbrio e invisibilidade de determinadas vozes no campo das artes.

A análise revelou que a raça negra possui inexpressiva representatividade enquanto identidade dos artistas, ao passo que a raça branca é hegemônica no período analisado. O mesmo desequilíbrio ocorre com o gênero feminino e masculino, estando o último em escala superior em todas as ex- 
posições aferidas. Se partirmos para um olhar interseccional, isto é, se analisarmos os artistas não brancos e do gênero feminino, o resultado é a nula representatividade deste grupo.

Acredito que a arte, enquanto reflexo do posicionamento do artista frente ao seu universo, deve ser não hegemônica e, portanto, dar visibilidade a artistas plurais enquanto raça, gênero, classe e sexualidade.

Não raro escutamos que a visibilidade desses sujeitos margeados não acontece devido à inexistência desses perfis nos mais variados campos, porém sempre nos questionamos se tal dado opera como justificativo pífio de indivíduos inseridos em uma sociedade patriarcal calcada em racismo institucional. Para tal argumento também trazemos o caso do Baltimore Museum of Art (BMA), segundo matéria do jornal digital Nexo, publicada em 04 de julho de 2018. O BMA em maio de 2018 vendeu obras de artistas - homens brancos renomados - que faziam parte de seu acervo, com o intuito de fazer caixa para adquirir obras feitas por artistas negros e mulheres.

Mandela (2009), ao discorrer sobre os Ashantis, grupo étnico de Gana, nos indica que aqueles ao concluírem seus contos folclóricos, costumam dizer: "essa que relatei é minha história; se for doce ou não, leve-a para alguém mais e deixe que parte dela retorne até mim".

Parafraseando os Ashantis concluo: este é o meu artigo, sendo doce ou não, espero que esses dados voltem a mim, porém com novas perspectivas de visibilidade.

\section{REFERÊNCIAS}

CASTELLS, Manuel. O Poder da Identidade. 3.ed.Rio de Janeiro: Paz e Terra, 1999.

CARTERS, The. Apes**t - The Carters. 16 Jun 2018. Disponível em: <https://www.youtube. com/watch?v=kbMqWXnpXcA>. Acesso em: 05 Jul 2018.

CANCLINI, Néstor García. A Sociedade sem relato. Tradução Maria Paula Gurgel Ribeiro. São Paulo: Editora da Universidade de São Paulo, 2012.

FÁBIO, André. Nexo. Este museu vendeu obras de brancos e comprou de negros e mulheres. Disponível em: <https://www.nexojornal.com.br/expresso/2018/07/04/Este-museu-vendeu-obras-de-brancos-e-comprou-de-negros-e-mulheres>. Acesso em: $05 \mathrm{Jul} 2018$.

FLUSSER, Vilém. O universo das imagens técnicas - elogio da superficialidade. São Paulo: Annablume, 2008.

HALL, Stuart. A identidade cultural na pós-modernidade. Tradução de Tomaz Tadeu da Silva e Guacira Lopes Louro. Rio de Janeiro: Lamparina, 2015.

MANDELA, Nelson. Meus contos africanos - seleção Nelson Mandela. Tradução Luciana Garcia - 2. Ed. - São Paulo: Martins Fontes, 2009. 
MBEMBE, Achille. Crítica da razão negra; tradução Sebastião Nascimento. São Paulo: n-1 edições, 2018.

MUNANGA, Kabengele. Uma abordagem conceitual das noções de raça, racismo, identidade e etnia. In: SEMINÁRIO NACIONAL DE RELAÇÕES RACIAIS E EDUCAÇÃO,3., 2003, Rio de Janeiro: PENESB,2003.

SOUZA, Arivaldo Santos de. Racismo institucional: para compreender o conceito. Revista da Associação Brasileira de Pesquisadores/as Negros/as (ABPN), [S.I.], v. 1, n. 3, p. 77-88, fev. 2011. ISSN 2177-2770. Disponível em: <http://abpnrevista.org.br/revista/index.php/revistaabpn1/article/view/275>. Acesso em: 01 jun. 2018.

ORGANIZAÇÃO DAS NAÇÕES UNIDAS. Grupo de trabalho da ONU sobre afrodescendentes divulga comunicado final sobre visita ao Brasil. Disponível em: $<$ https://nacoesunidas.org/grupo-de-trabalho-da-onu-sobre-afrodescendentes-divulga-comunicado-final/>. Acesso em 01 de junho de 2018.

SCHWARCZ, Lilia Moritz. Racismo no Brasil. São Paulo: Publifolha, 2001.

WARNKE, Martin. $O$ artista na corte. São Paulo: Editora da Universidade de São Paulo, 2001. 
CADERNOS DE COMUNICAÇÃO

UNIVERSIDADE FEDERAL DE SANTA MARIA

\section{Manuela Thamani}

Mestranda em Interfaces Sociais da Comunicação da Escola de Comunicação e Arte da Universidade de São Paulo. Realiza pesquisas no âmbito da comunicação/educacação, a partir de uma perspectiva de raça e gênero. E-mail: manuelathamani@gmail.com 